\title{
Enhancing collaboration through web enabled performance measurement system
}

Sai S. Nudurupati, Umit S. Bititci and Stephen Maddocks

CSM, DMEM, University of Strathclyde, UK.

\begin{abstract}
There are several frameworks and models available on performance measurement but current Management Information Systems (MIS) available in the enterprises are not sufficient to support these frameworks and models. Hence, the paper includes a review of the commercial software available to support performance measurement frameworks and models. From the results of this review, there is a requirement for a new approach called Web enabled Performance Measurement System (WePMS). The paper demonstrates the design and architecture of WePMS and implements it in two companies in action. Finally the paper discusses several scenarios in which WePMS had enhanced the enterprise collaboration with its customers and suppliers.
\end{abstract}

Keywords

Performance Measurement, Collaboration, IT, Statistical Quality Control.

\section{INTRODUCTION}

There is lot of literature in the field of performance measurement, which includes several frameworks, models, tools and techniques etc. as well as implementations of these. Even though there are several commercial IT platforms emerging in the market, there is a lack of research in IT platforms or Management Information Systems (MIS) designed from the company's in-house available resources to support Performance Measurement. Hence, the objective of this paper is to demonstrate how organisations (SMEs) can build an effective IT / Web enabled Performance Measurement System (WePMS) that enhances collaboration with suppliers and customers, with minimum investment. The paper includes two action case studies that demonstrate the implementation of IT based Performance Measurement and the implications it had on collaboration with suppliers and customers.

The paper starts with a background on Performance Measurement literature, which also includes a discussion of current MIS in the SMEs and pinpoints their limitations. A review is presented on commercial software available for performance measurement based on a standard criteria obtained from five Scottish based SMEs that are interested in implementing WePMS. The findings of this review are that the current commercial software cannot fulfil all the requirements of these enterprises. 
Hence, it is concluded that there is a need to design WePMS that fulfils all the criteria.

Following the background, the research methodology is briefly described. Later, a general architecture for WePMS is designed and explained in detail. This designed WePMS is implemented in two companies. The benefits gained by each company are discussed. Based on these cases, the paper describes different scenarios by which WePMS can effect collaboration with customers and suppliers. Finally, it closes the paper with a discussion and conclusion.

\section{BACKGROUND}

\section{Performance Measurement}

The performance measurement revolution started in the late 1970s and early 1980s with the dissatisfaction of traditional backward-looking accounting systems. Since then, a number of frameworks, as well as tools and techniques, have evolved, some of which are: Active Monitoring (Turner and Bititci, 1997), Balanced Scorecard (Kaplan and Norton, 1992 \& 1996), Cambridge Performance Measurement Systems Design Process (Neely et al, 1996), Deming Award (1950), European Foundation for Quality Management (EFQM) Excellence Model (1991), Integrated Dynamic Performance Measurement System (IDPMS) (Ghalayini et al, 1997), Integrated Performance Measurement System Reference Model (Bititci et al, 1998), Malcolm Baldrige Award (1987), Performance Measurement Questionnaire (Dixon et al, 1990), Performance Prism (Neely et al, 2001), Strategic Measurement and Reporting Technique (SMART) Model (Cross K F and Lynch R L, 1988 1989), Quantitative Methods for PMS (Suwingnjo et al, 1998)

Even though there is considerable amount of research being carried out in this area (frameworks and models), most of these implementations of Performance Measurement Systems fail (Hudson et al, 2001, Bititci et al, 2000, Bourne 2000, and Bierbusse et al, 1998) because of the following reasons:

- Lot of time and investment required

- Very difficult to quantify results in areas that are more qualitative in nature

- Large number of measures, which are very difficult to be managed on manualbased performance measurement system

* The lack of proper information system

Most of the reasons mentioned above will convey the same message that there is a lack of proper Management Information Systems (MIS) available in enterprises to support PMS and enhance its collaboration with suppliers and customers.

\section{Management Information Systems (MIIS) in Enterprises}

Most of the modern MIS have been developed to provide management with the right information required. However, most of today's MIS store information in different sources (McNurlin et al 2002, Garnett 2001), such as legacy systems, ERP systems, spreadsheets, databases, etc. In some enterprises the information is even 
maintained on paper based sources. The problems encountered with these systems are:

- Lack of visibility because information is hidden (McNurlin et al 2002)

- Difficulties associated with gathering information from different sources (i.e. time and effort required to extract sort and report information) (Garnett 2001)

- Lack of proper links between different sources of information (Garnett 2001)

- Lack of effective communication of the information (McNurlin et al 2002)

- Changes and trends occurring are not transparent to everyone concerned

As a result of these problems, enterprises need to invest much of their time in data gathering. As the data is stored in different formats in different departments, some of the data is duplicated (Garnett 2001) and updated by different people. Hence, questions always arise on the validity of data. As information sources are not linked properly, information is not available dynamically (i.e. near real-time), which does not allow managers to make fast and confident decisions. As information is not shared or communicated throughout the organisation, managers cannot work as a team and changes occurring in one source are not transparent to everyone. This often leads to a reactive and closed management style, pointing fingers at one another rather than focusing on the issue in hand.

The limitations of existing performance measurement systems are also relevant in the context of collaboration. On one hand, customers will be interested in looking at the process data to either vary the composition of raw material, adjust the process or re-deploy-resources, which would otherwise affect the final quality of their product, on the other hand the suppliers will be interested in seeing the same data to improve the quality of raw material. Apart from quality, there are several issues in which the suppliers and customers would be interested in, such as delivery times, total cycle times, amount of scrap, number of orders, etc. Unless the performance information is properly structured, made easily accessible and disseminated in a relevant manner, it cannot be shared across the supply chain to enhance collaboration.

\section{Commercial Software Platforms for Performance Measurement}

Currently there is a revolution in the market with several software vendors developing their application/product to support the performance measurement, although most of them are based on Balanced Scorecard. These performance measurement software applications are developed for data communication, integration, analysis and representation to different sets of audience, including suppliers and customers, to enhance collaboration on the supply chain. In the last decade, there has been an enormous growth in the number of software applications offered for performance measurement, which caused the users difficulty in distinguishing between these applications.

In order to understand these software platforms (not necessarily the Balanced Scorecard) in depth, The Centre for Strategic Manufacturing at the University of Strathclyde has done a structured review (Nudurupati 2002) based on the user requirements gathered from five Scottish based enterprises (SMEs). The products offered by the above vendors are classified into three categories: 
Business Intelligence (BI) is a continuous and systematic process, which produces information on a company's operating environment in a timely manner and usable form so that it can have positive impact on business processes. Effective Business Intelligence will facilitate the improvement of business processes and reduces the time used for decision-making. Typically, it includes software functions, such as data sourcing, data analysis, risk assessment, decision support, etc. It includes software tools, such as Data Marts, Data Warehousing, On-line Transactional Analysis tools, Multidimensional Databases or On-Line Analytical Processing (OLAP) tools, Adhoc and Prepackaged Query tools, etc. Typical BI platforms are provided by: Oracle Corp., Hyperion, SAS Institute, Cognos Ltd., Pilot Software Ltd, SAP Ltd., PeopleSoft, CorVu Plc., Gentia Software Ltd., Comshare etc.

Enterprise Resource Planning (ERP) Platforms: An ERP system is a multimodule software system that includes a central relational database and several software modules for managing purchasing, inventory, production, personnel, shipping, customer service, financial planning, and other important aspects of the business. Some ERP vendors started to integrate performance measurement as a module or feature within their ERP platform, e.g. SAP Ltd., PeopleSoft, Oracle Corp. Ltd. etc.

Dedicated Performance Measurement Platforms: These are software platforms that allow organisations to implement performance measurement frameworks, such as Balanced Scorecard, EFQM, etc. Typically, it collects the performance relevant information from different sources, analyses the information and communicate the information to different stakeholders who make decisions. Vendors of dedicated performance measurement platforms include PB Views Ltd., QPR Software Plc., Inphase Software Ltd., Hyperion, Cognos Ltd., Lucidus Ltd., PT. Global Performa Maxima, Gentia Software Ltd., IPS-Sendero, Comshare, Active Strategy etc.

Even though ERP platforms were classified separately, vendors who offer performance measurement within ERP modules are not yet common and most of the IT based PMS applications are built upon BI or Dedicated platforms that have the capability of integrating with companies existing ERP and other systems. Hence, the remainder of this paper will focus on BI and Dedicated platforms to performance measurement.

A review of $\mathrm{BI}$ and Dedicated platforms to performance measurement was conducted by the researchers. The criteria used to evaluate these platforms was developed through educating management of five SMEs on performance measurement and best practice applications of PMS and then facilitating them to develop a requirements specification based on how they would see themselves using the system.

Even though BI solutions are very good at slicing and dicing the information, the solution itself is very expensive for the sake of performance measurement in SMEs. Most of these solutions are also not capable of incorporating statistical analysis as required by Six Sigma. As more and more companies are adopting the Six Sigma business improvement approach as a foundation of their continuous improvement programmes (Chowdhury 2001), the capability to analyse performance of business and manufacturing processes using six sigma tools is becoming increasingly a more critical requirement. The dedicated platforms for performance 
measurement are also expensive and they share a lot of the limitations of the BI platforms, specifically with respect to supporting Active Monitoring and Six Sigma approaches.

As we mentioned earlier, the review was conducted based on the requirements of five SMEs, four of which had expressed their dissatisfaction with the available software platforms for the following reasons:

a The cost for most of software products are extremely high ranging from $£ 30 \mathrm{k}$ or upwards, excluding Development, Consulting and Training costs.

- Flexibility of the software platforms on offer.

- Most of the software is not good at controlling processes using statistical approaches (as required by the Six Sigma and many TQM approaches).

Hence, in order to meet the objective of the research, i.e. to demonstrate how organisations can build effective IT / Web based Performance Measurement System (WePMS) that enhances collaboration with suppliers and customers, with minimum investment, it was deemed necessary to develop a web-based performance measurement platform using standard, low-cost, software products without using any of the BI or Dedicated software platforms reviewed.

\section{METHODOLOGY}

Figure 1 explains the methodology adopted in this research. 


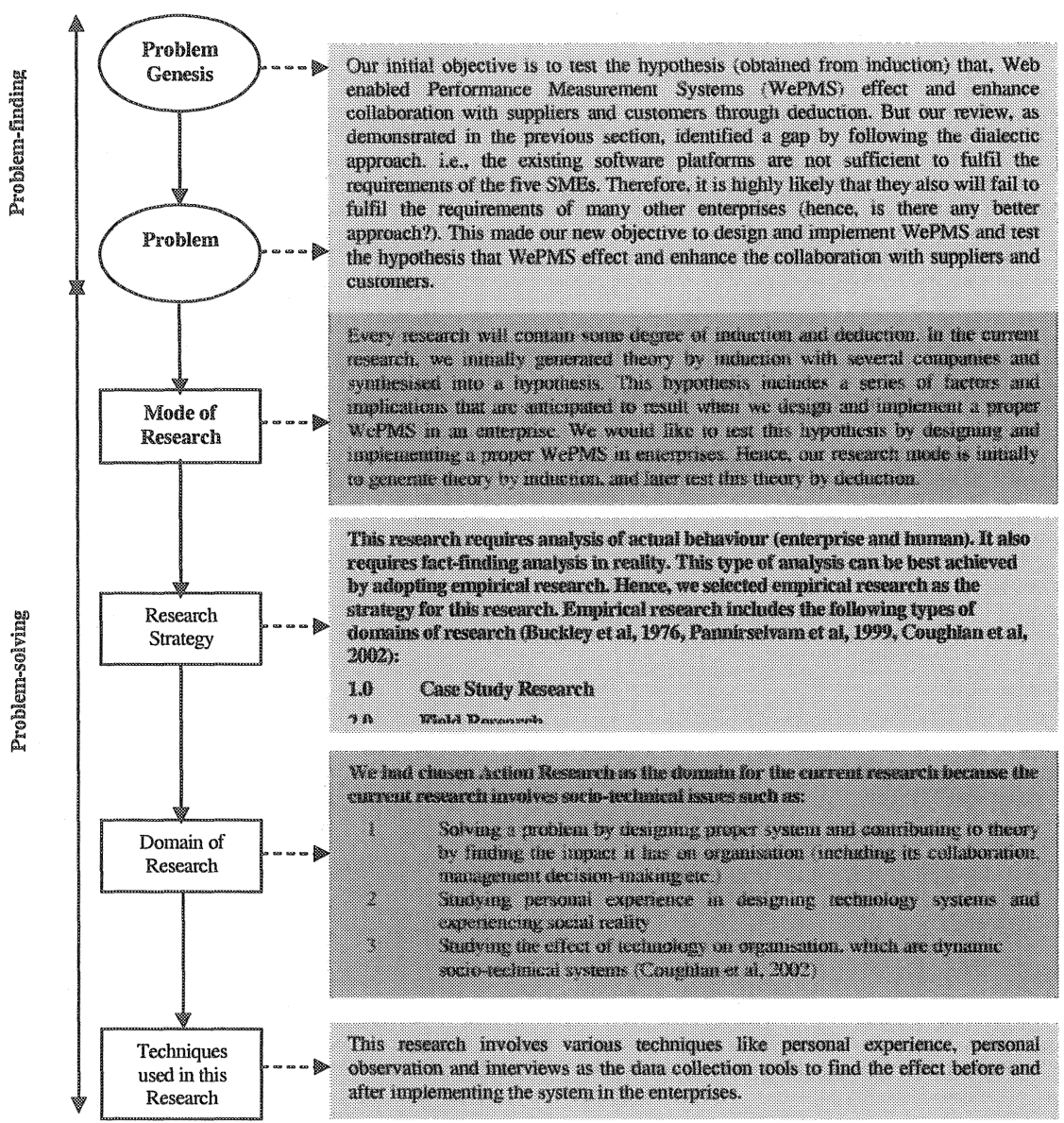

Figure 1 - Research Methodology Framework (Buckley et al, 1976

\section{WEB ENABLED PERFORMANCE MEASUREMENT SYSTEM}

With the dissatisfaction of the five-user SME enterprises on the results obtained from the software review, we extended our search for other approaches, which minimises the cost and provides more of a process control techniques and tools. At the same time it should deliver a complete solution for WePMS that enhances collaboration with customers and suppliers. Based on the user requirements gathered, we identified architecture for Web enabled Performance Measurement System (WePMS) was developed as shown in the Figure 2. 


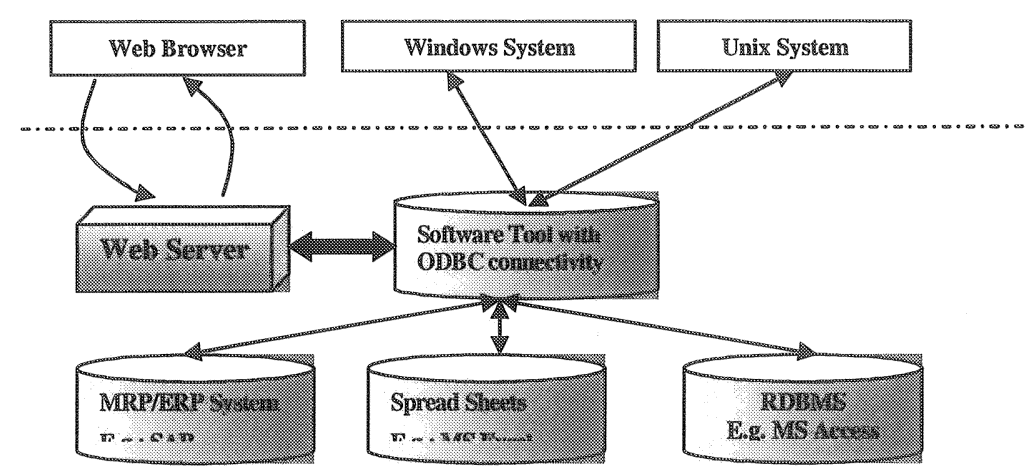

Figure 2 - Architecture for Web enabled Performance Measurement System.

In developing this architecture and selecting the software tools to be used, the objective is to fulfil the requirements stated earlier in the paper. A key requirement was that any information entered into any system, such as Manufacturing Resource Planning (MRP) System, Spread Sheets, RDBMS etc., should be accessible by the software tool through Open Data Base Connectivity (ODBC). This tool should then be able to produce the data in a more meaningful form, such as SQC charts, Statistical analysis, Summary Reports, etc. The users must be able to access this information from anywhere, through security authorisation.

Further investigation revealed that any good SPC software or Spreadsheet software is able to fulfil the majority of the requirements as long as it is configured and used in an appropriate manner and facilitated through appropriate web pages for browsing and data entry. The two alternative approaches are, as shown below:

- Using simple Statistical Process Control (SPC) tools available together with the

in-house IT capabilities (Internet Explorer, Internet Information Server, etc.) of the end-user enterprises to develop WePMS.

Developing WePMS, using the organisations in-house technology (e.g. Excel spreadsheets, Internet Explorer, etc.)

We have used each of these tools to develop a WePMS. We used MS Excel as the Spreadsheet software and Northwest Analytical Quality Analyst Web Server (NWA QAWS) as the SPC software. Then we tested each of these approaches through workshops with a number of companies. Based on our experience and on the feedback from the companies, we came to a number of conclusions that are illustrated in Table 1.

Table 1 - Limitations of MS Excel against SPC software

\begin{tabular}{|l|l|}
\hline \multicolumn{1}{|c|}{ Using MS Excel } & \multicolumn{1}{|c|}{ Using NWQA } \\
\hline $\begin{array}{l}\text { It takes a significant amount of time and } \\
\text { effort to prepare it for SPC/SQC use }\end{array}$ & $\begin{array}{l}\text { It does not require much time and effort as } \\
\text { it is a tool developed for this purpose }\end{array}$ \\
\hline $\begin{array}{l}\text { It requires macro writing and } \\
\text { programming to automate the analysis }\end{array}$ & $\begin{array}{l}\text { It is very easy to automate the analysis } \\
\text { with it, as the programming and logic are } \\
\text { pre-built in the system }\end{array}$ \\
\hline $\begin{array}{l}\text { It requires knowledge of SPC/SQC to } \\
\text { develop the application with Excel }\end{array}$ & $\begin{array}{l}\text { The logic is pre-built into the system, } \\
\text { users can use it with the help of user } \\
\text { friendly wizards }\end{array}$ \\
\hline
\end{tabular}




\begin{tabular}{|l|l|}
\hline $\begin{array}{l}\text { It requires training in using this } \\
\text { SPC/SQC analysis, but there are no such } \\
\text { media available to train users (even } \\
\text { though Excel provides help in using it, it } \\
\text { does not provide help for SQC/SPC } \\
\text { analysis) }\end{array}$ & $\begin{array}{l}\text { It provides help files and user manuals to } \\
\text { train people in using SPC/SQC analysis }\end{array}$ \\
\hline $\begin{array}{l}\text { Charts produced in Excel are of poor } \\
\text { quality and also time consuming (while } \\
\text { adjusting the parameters, size of the chart } \\
\text { etc. It requires a tremendous amount of } \\
\text { effort to get what you want) }\end{array}$ & $\begin{array}{l}\text { It produces charts of high quality at a } \\
\text { mouse-click }\end{array}$ \\
\hline $\begin{array}{l}\text { Excel spreadsheets do not tell what the } \\
\text { user needs to do to draw an SQC chart. It } \\
\text { is also very confusing to use Excel for } \\
\text { this analysis }\end{array}$ & $\begin{array}{l}\text { It produces a user-friendly interface, } \\
\text { done to draw an SQC chart. It is straight } \\
\text { forward in using it }\end{array}$ \\
\hline $\begin{array}{l}\text { It requires complex queries to import } \\
\text { data from external sources and also, it } \\
\text { does not allow this import from many } \\
\text { databases }\end{array}$ & $\begin{array}{l}\text { It provides a user-friendly interface and } \\
\text { pre-built queries to import data from other } \\
\text { databases. It can import data from any } \\
\text { ODBC compliant software }\end{array}$ \\
\hline $\begin{array}{l}\text { Sometimes it become very difficult and } \\
\text { cumbersome to update (add or delete } \\
\text { columns etc.) and reprogram the analysis }\end{array}$ & $\begin{array}{l}\text { It is very easy to update and reproduce the } \\
\text { charts and analysis }\end{array}$ \\
\hline $\begin{array}{l}\text { It is not possible to do the analysis and } \\
\text { charts through the web as it does not } \\
\text { include any Web Server }\end{array}$ & $\begin{array}{l}\text { It is possible to do this analysis and charts } \\
\text { through the web if it includes a Web } \\
\text { Server-In the case of NWQA, a web- } \\
\text { server is included in the package. }\end{array}$ \\
\hline
\end{tabular}

Table 1 clearly demonstrates the advantages of using SPC software packages in contrast to using spreadsheet products. Hence, it was decided that an SPC software would be used to create the above architecture. There are several SPC software products available and emerging in the market, some of these are: SPC Pack 2000 (including Chart Runner) from PQ Systems Ltd., QA - Active SPC from Quality America, Inc., SPC / PI + from Qualitran Professional Service, Inc., SPSS from SPSS, Inc., NWA QAWS from Northwest Analytical, Inc. Most of the software mentioned above are offered at almost the same price with similar functionality. We have chosen NWA QAWS for our implementation because of its availability, ease of use and flexibility, as well as its web publishing capability. Its features will be described more in detail in the following sections.

\section{IMPLEMENTING WEPMS IN COMPANY A}

Company A based in Glasgow is a profit centre. The site specialises in the manufacture of thin aluminium foil (such as those used for cooking, food and confectionery packaging) and laminated aluminium foil (such as those used in cigarette packaging). The main processes within the factory are rolling and laminating.

The IPMS Reference Model (Bititci and Carrie 1998) was used to guide the management team to identify and structure the key performance measures. The heart 
of the WePMS implemented at Company A is the Quality Analyst software product, which is essentially a software platform designed specifically for supporting statistical process control applications. It provides the best combination of power, flexibility, and ease of use. It conforms to the most stringent technical requirements and easily integrates into manufacturing data systems. It produces all standard SPC charts plus many special-purpose charts. It allows us to dig into the information by "drilling down" into the charts.

With the Open Data Base Connectivity (ODBC), Quality Analyst can pull down data from different sources into its own database. In this case it is being used as a tool to collect and convert numerical data into graphical shewhart charts (more commonly known as SPC charts). In Company A the data was available from a number of sources including: MRPII system, Spreadsheet applications, i.e. MS Excel, Database applications, i.e. MS Access, Machine controllers, Data loggers

Figure 3 illustrates this structure where Quality Analyst provides the main interface between the web pages and the data source. This architecture enables the following:

- Creation of data, either automatically (through the MRPII system, machine controllers and the data loggers) or manually (through spreadsheets and databases)

- Annotation of data, either manually (e.g. by providing a comment field within the database or spreadsheet) or automatically (through reason codes that may be available within the existing systems)

- Viewing information through Company A's intranet pages

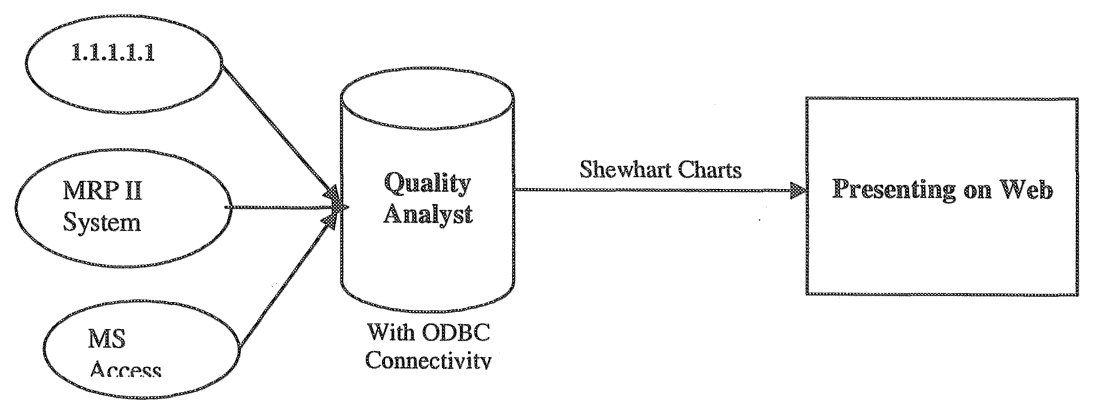

Figure 3 - Architecture of the WePMS at Company A

In Company $\mathrm{A}$ the WePMS is known as the Management Team Reporting (MTR) System. Figure 4 illustrates a sample of the performance reports available through the MTR System. 


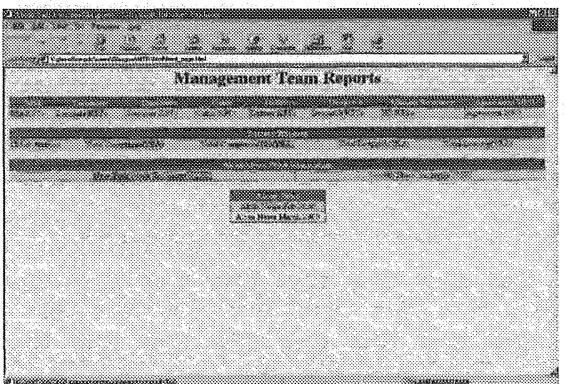

(a) Menu Page

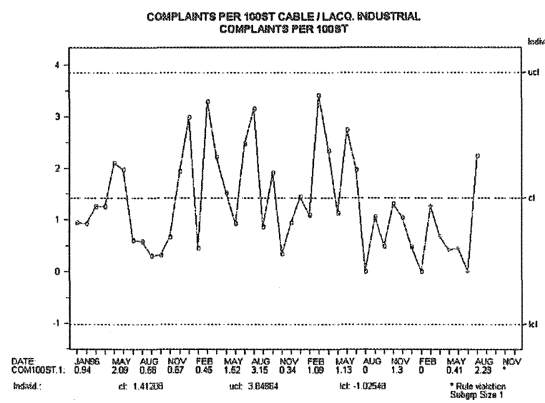

(c) Customer complaints (monthly)

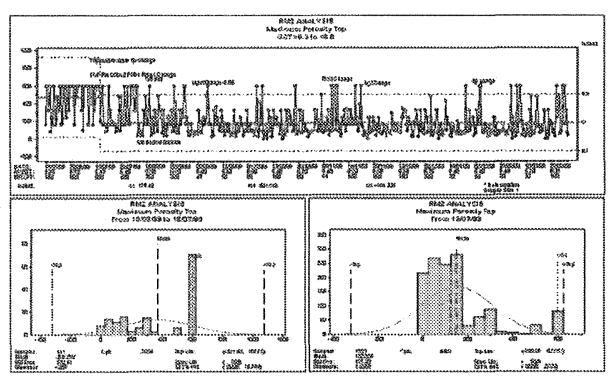

(b) Porosity (daily)

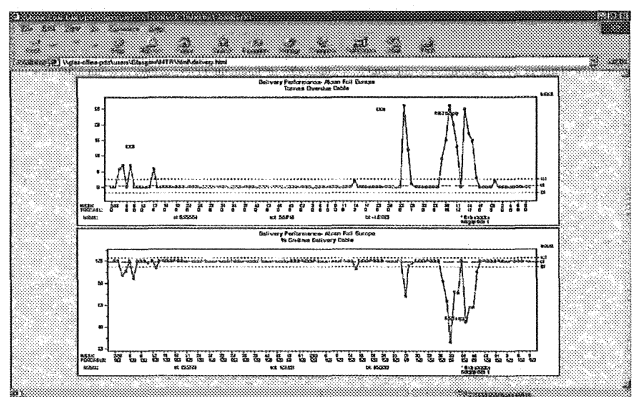

(d) Delivery performance (weekly)

Figure 4 - Sample pages from the Company A's MTR System (WePMS).

The web-page in Figure 4a illustrates the main menu page providing access to performance reports for various parts of the business. In Figure $4 b$, the top chart illustrates a shewhart chart for monitoring variations in the porosity during the rolling process. This is a critical technical measure captured by the data loggers on a continuous basis and the daily averages are reported automatically by the MTR system at the end of each day. The Figure also illustrates that the tolerances were tightened in July 1999. Annotations communicate that the targets are not achieved, indicating the reasons, such as paper change, roll change etc. The bottom charts illustrate the process capability histograms, one before tightening the tolerances and the other after tightening the tolerances.

The web-page in Figure 4c illustrates AFE's performance with respect to customer complaints received each month. This information is captured manually. As customer complaints are received by the customer services department they are entered into a customer complaints log (MS Access Database), in accordance with the Company's ISO9000 procedures. Quality Analyst picks this information from the database and presents it on the web-page. The chart in Figure 1c shows customer complaints received by AFE.

Figure 4d illustrates two charts, one illustrating a backlog against customer orders and the other illustrating delivery performance against customer orders. The chart shows that delivery performance has been within target of $95 \%$, except between weeks 36 and 41, where delivery performance has suffered considerably due to a problem with the raw material supply (as annotated). 


\section{Overall benefits of WePMS on Company A:}

Figure 5 summarises the results of the feedback received by interviewing a selected cross-section of employees (managers, engineers and operational staff) in Company A.

\begin{tabular}{|c|c|c|c|c|c|c|}
\hline No & Question & 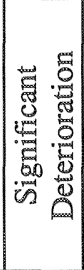 & 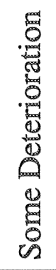 & 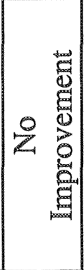 & 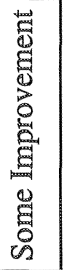 & 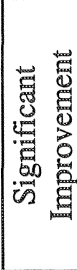 \\
\hline 1 & The business benefits of the WEPMS & & & & 栜 & \\
\hline 2 & The impact of WePMS on business performance & & & & 楼 & \\
\hline 3 & Confidence in manager's decisions & & & & & 舞 \\
\hline 4 & Management style-proactive & & & & 泪 & \\
\hline 5 & Effect on the behaviour of management & & & & & 潣 \\
\hline 6 & Effect the behaviour of operational staff & & & & 粗圈 & \\
\hline 7 & Effect on the team behaviour-management & & & & 溗每 & \\
\hline 8 & Effect on the team behaviour-operational staff & & & & 满国 & \\
\hline 9 & Effect on dissemination of knowledge & & & & & 滥 \\
\hline 10 & Effect on visibility of information & & & & & \\
\hline
\end{tabular}

Figure 5 - Summary of structured interviews.

\section{IMPLEMENTING WEPMS IN COMPANY B}

Company B, based in Edinburgh, UK, was founded in 1858 and has a vast experience in producing different types of labels using digital and combinations press technology.

The company has a scheduling and data collection system, Shuttleworth, which collects the data (such as Date, Shift No, Job No., Machine Speed, Raw Material Fed, Useful Output, etc.) from the shop floor and stores it in a 17 year old Speed Base Development System (SBDS). SBDS is a non-relational database system, which is not user-friendly and the IT Manager is the only person who can use it effectively. This seriously limited access, potentially to a very useful data. Information had to be requested from the IT Manager in the specified format but, as SBDS is not a relational database, it was not always that easy to format data in specified fashion.

On an informal basis, employees started using raw data from SBDS to do the analysis using MS Excel, MS Access, etc. As there was no consistent approach to performance analysis, different people came up with different results, which resulted in doubts on the validity of data and information. Although the company had an intranet, it was not used for performance analysis reports. Manual methods were used to print reports, which were displayed on the notice boards. 


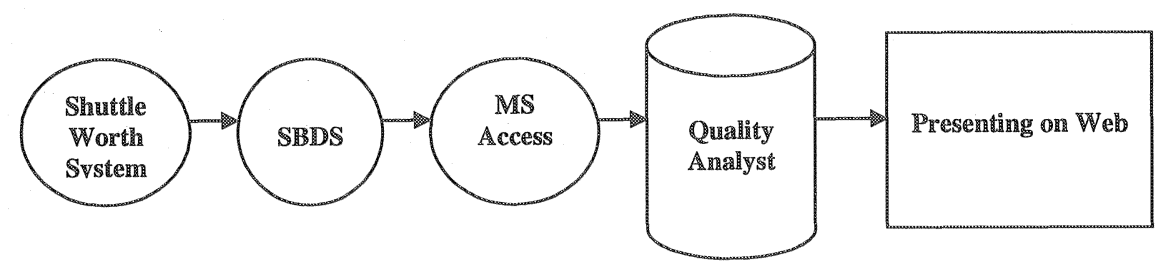

Figure 6 - Architecture of the WePMS at Company B

In October 2001, the researchers presented their work with Company A to the management team in Company B, who decided to adopt and implement WePMS using Balanced Scorecard and NWA Quality Analyst Web Server Software (on a pilot basis) to deploy operational PMS using Overall Equipment Effectiveness $(\mathrm{OEE})$ as a firewall. This meant measuring the availability, performance, quality and OEE of each machine and OEE for the whole factory on a daily and weekly basis. The architecture of the resultant WePMS is shown in Figure 6

Several queries are written in MS Access to get the desired output, such as availability, performance, quality and OEE on daily and weekly basis. Later these measures were displayed as Shewhart charts and summary reports on the company's intranet. The information is dynamically available to the users. Once they click a button on the web page, as shown in the Figure $7 \mathrm{a}$, the software platform automatically connects to the MS Access database and gets that information in the form of a statistical quality control chart, as shown in Figures $7 \mathrm{c}$ and $7 \mathrm{~d}$ as well as summary reports as shown in Figure 7b, which includes summary characteristics at the end of the report such as Mean, Standard Deviation, Best Value, Poor Value etc.

The WePMS implementation started in Week 42 and completed in week 50. In Figure 7c, the chart represents the OEE Performance of the whole factory (all machines) before Week 42 (prior to implementation). The OEE Performance measure is almost constant, as the company did not have chance to calculate OEE and hence they really find difficult to assess whether they are improving or not. Now after implementing WePMS system during Week 42 to Week 50, which now has the capability to produce information up-to-date to promote continuous improvement in the company, as shown in the Figure 7d. This improvement in Performance of the factory has improved the OEE, which has reflected in their financial sheets with improvements. This also gained Marketing and Financial Manager's confidence in the system.

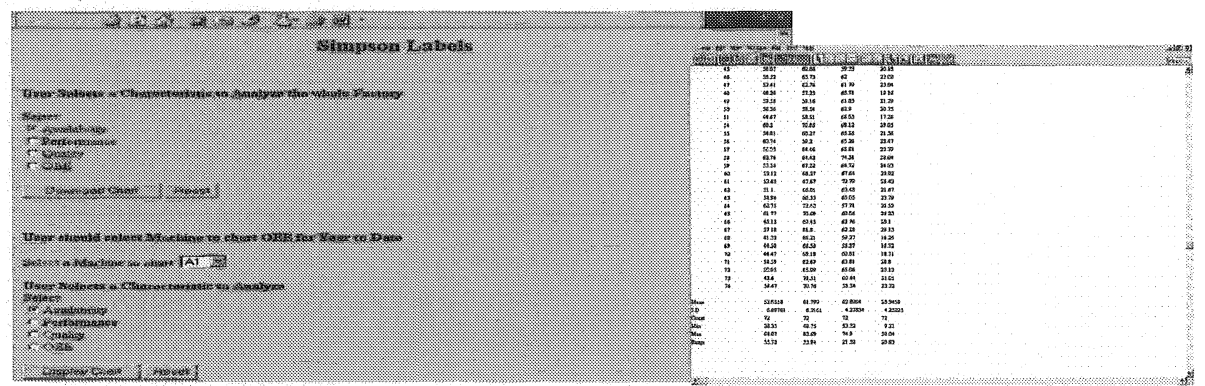

(a) Menu Page

(b) Shewhart chart on OEE and Performance 


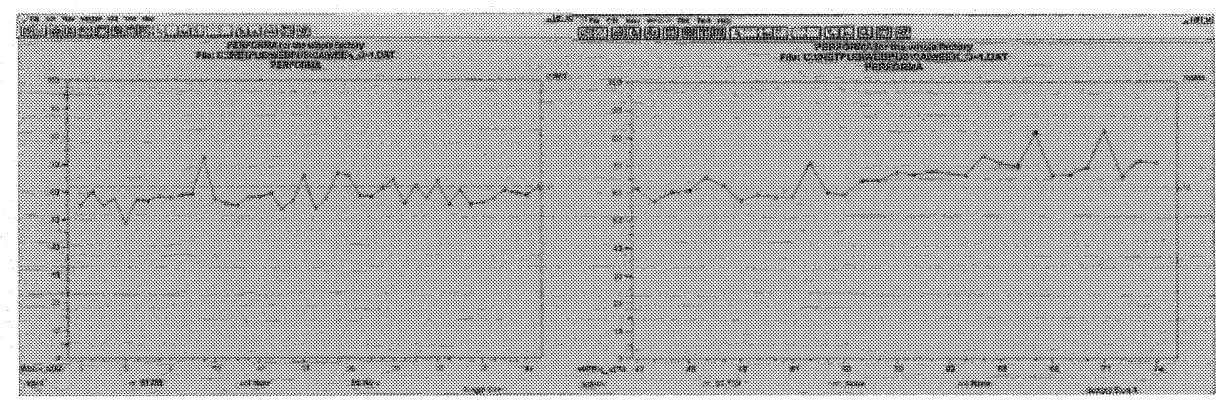

(c) Shewhart chart OEE Performance (Week 1 to Week 42)

(d) Shewhart chart OEE Performance (Week 42 to Week 74 (to date)

Figure 7 - Sample pages available on the Intranet of Company B.

The examples of performance reports shown in Figure 7 are the OEE measures for the whole factory on a weekly basis. The system provides the capability to drill down OEE (including availability, performance and quality) as follows:

» for each machine on a daily and weekly basis

w for the whole factory on a daily and weekly basis

- measuring down times for each machine on daily and weekly basis

It is the machine level information that is being used to drive continuous improvement within manufacturing operations of this business.

\section{Overall Benefits of WePMS on Company B:}

Figure 8 summarises the results of the feedback received by interviewing a selected cross-section of employees (managers, engineers and operational staff) in Company B

\begin{tabular}{|c|c|c|c|c|c|c|}
\hline No & Question & 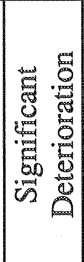 & 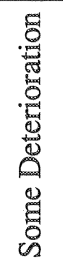 & 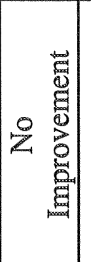 & 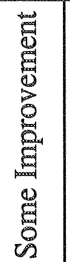 & 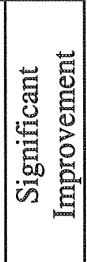 \\
\hline 1 & The business benefits of the WePMS & & & & 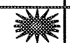 & \\
\hline 2 & $\begin{array}{l}\text { The impact of WePMS System on business } \\
\text { performance }\end{array}$ & & & & 畨 & \\
\hline 3 & Confidence in manager's decisions & & & & & 澲 \\
\hline 4 & Management style-proactive & & & & & 带萧 \\
\hline 5 & Effect on the behaviour of management & & & & 漺 & \\
\hline 6 & Effect the behaviour of operational staff & & & & 滥 & \\
\hline 7 & Effect on the team behaviour-management & & & & 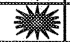 & \\
\hline 8 & Effect on the team behaviour-operational staff & & & & 㴗魚 & \\
\hline 9 & Effect on dissemination of knowledge & & & & & \\
\hline 10 & Effect on visibility of information & & & & & 齐 \\
\hline
\end{tabular}

Figure 8 - Summary of structured interviews. 
In contrast to the results of Company $\mathrm{A}$, the WePMS implementation in Company B seems to have resulted in some improvements, but not as significant as in Company A. Based on our observations and discussions with the management team in company $\mathrm{B}$, the main causes of this are:

- In Company A WePMS is implemented company wide but in Company B it is linked to the Operations (Manufacturing and Engineering) of the company

- The system is in its infancy at the time of writing - the new WePMS was being used as a performance monitoring and improvement tool for only two months

- We would, therefore, anticipate that the observed benefits will be significant as the WePMS beds in, and as it is expanded to cover all aspects of the business.

\section{WEPMS: IMPLICATIONS ON COLLABORATION}

Although the WePMS, in both cases, was implemented to improve monitoring as well as improve business and operational performance, it is shown a potential tool to facilitate and enhance collaboration with the companies' suppliers and collaborators. Following examples show how this can be achieved.

- In the case of Company A, one of the technical (process) based performance measures was shared with one of their key customers. This resulted in two actions that resulted in the improvement of its business. Consequently, this particular customer decided to place all of their orders for this potential range of products with Company $\mathrm{A}$ :

1. A joint improvement initiative to improve the Company's performance against this particular measure

2. The customers realised that having real time access to the critical process information allowed them to vary their own process parameters, thus resulting in more consisted products and production output

- Providing access (albeit it may be limited) to customers, to key performance information on product / process performance, customer service performance (e.g. OTIF, lead times etc.) could help building openness and foster collaboration culture.

a Providing detected performance information to suppliers on their performance (such as quality, delivery reliability, delivery speed etc.) could emit the supplier to improve its own performance with respect to that specific customer business.

- For a given product range, a number of suppliers' performance information could be summarised and presented on the intranet as a report for all of the concerned suppliers to see. The electronics industry has used this approach for some years through operating business reviews where WePMS could enhance this process by making it continuous, thus facilitating a greater degree of collaboration and healthy competition within the supply chain.

- In the case of Extended Enterprises (EE) and Virtual Enterprises (VE), it is critical that the performance objectives and achievements of various organisations along the $\mathrm{EE}$ or $\mathrm{VE}$ are consistent and complementary to the performance objectives of the overall $\mathrm{EE}$ or VE. In this context, sharing of key performance information between members of the $\mathrm{EE}$ or VE becomes critical 
and Web enabled PMS becomes crucial in efficient and effective sharing of information.

\section{DISCUSSION AND CONCLUSIONS}

The results of this research may be summarised as follows. The web-enabled performance measurement system, when implemented in both the enterprises resulted in significant benefits:

- Improving collaboration with customers and suppliers

a Providing up-to-date information

- Making performance information more transparent and visible internally within the enterprise as well as along the supply or demand chain

m Providing an open communication channel to both internal and external users, including sister plants, parent companies, etc.

w Improving accuracy, reliability and credibility of performance information

w Creating awareness of issues and focus on critical problems along the demand chain

* Creating an understanding of the cause and effect relationship between the business measures and operational measures

- Facilitating better control (monitoring and improvement) of the performance of Extended or Virtual Enterprises.

Consequently, managers are:

- more confident with their decisions

a more efficient as a team

* enabling empowerment

more proactive in their management style

m promoting more partnerships between managers within and outside the organisations

- continuously improving the processes

The researchers opinion is that the majority of the benefits gained are not only attributable to WePMS but also to other factors, which played a significant role in its success. These are:

a Adoption of statistical process control charts as a standard method of documenting performance information. In a process plant where SPC techniques are widely understood this approach gained considerable support mainly due to familiarity and also due to visual and graphical nature of the charts.

v Senior management commitment at both the companies, by far, was one of the key influences that led to the success of these systems. The Managing Director at Company A insists that all personnel, when they are talking to him on performance related issues, use the WePMS. He said "I look at several charts several times every day, I ask questions to my managers and team leaders about them, I expect them to communicate to me using these charts". In our 
opinion it is his commitment that resulted in adoption of the WePMS as an everyday management tool.

- Extend the use of the WePMS into customers and suppliers, to solve some of the key issues resulting in mutually shared benefits.

This paper provided empirical evidence that appropriately designed performance measurement systems, if supported through appropriate IT platforms, will improve visibility, communications, teamwork, decision making and it will lead to a more proactive management style, not only within a single organisation but also throughout the company's supply or demand chain. Although this conclusion is based on two action cases, the authors are confident that the benefits enjoyed by them are replicable in other organisations provided that the environmental conditions are similar.

\section{REIERENCES}

[1] Bierbusse, P. and Siesfeld, T. (1998) "Measures that Matter", Journal of Strategic Performance Measurement, 1, 2, 1998, 6- 11

[2] Bititci U. S. and Carrie A. S., (1998), "Integrated Performance Measurement Systems: Structures and Relationships", EPSRC Final Research Report, Research Grant No. GR/K 48174, Swindon UK.

[3] Bititci U. S., Trevor Turner and Carsten Begemann (2000), "Dynamics of Performance Measurement Systems", International Journal of Operations and Production Management, MCB University Press, Vol.20 No.6 2000.

[4] Bourne M., Mills J., Wilcox M., Neely A. and Platts K., (2000) "Designing, implementing and updating performance systems" International Journal of Operations and Production Management, MCB University Press, Vol.20 No.7 2000.

[5] Bourne, M. C. S., (2001), The success and failure of performance measurement system design interventions, $\mathrm{PhD}$ Thesis, University of Cambridge, UK.

[6] Buckley W. John, Buckley H. Marlene, Chiang Hung-Fu, (1976) "Research Methodology \& Business Decisions" Published by National Association of Accountants, 919 Third avenue, New York, N.Y 10022 and The Society of Industrial Accountants of Canada, 154 Main St. E., Hamilton, Ontario, Canada

[7] Chowdhury Subir, "The Power of Six Sigma", Prentice Hall (2001)

[8] Coughlan P., Coghlan D., (2002) "Action research for operations management", International Journal of Operations and Production Management, MCB university Press Ltd., Vol. 22 No.2, pp $220-240$

[9] Cross K. F. and Lynch R. L., (1989) "The SMART way to define and sustain success", National Productivity Review, Vol. 9 No. 1, 1989, pp 23 - 33

[10] Dixon JR, Nanni AJ, Vollmann TE, (1990) "The new performance challenge: measuring operations for world class competition”, Dow Jones -Irwin Homewood 11.

[11] Garnett C. (2001), "Aged Pioneer to Retire - Gradually: New Clinical Research Information System Planned to Replace MIS", The NIH Record, Vol. LIII, No 21. 16 Oct 2001 at http: //www.nih.gov/news/NIH-Record/10 16 2001/main.htm (Dated: 13 Jun 02)

[12] Ghalayini A. M., Nobke J. S. and Crowe T. J., (1997) "An integrated dynamic performance measurement system for improving manufacturing competitiveness", International Journal of Production Economics 48 - 1997, pp207 - 225. 
[13] Hudson M., Smart A., Bourne M. (2001) "Theory and practice in SME performance measurement systems", International Journal of Operations and Production Management, Vol. 21 No. 8.

[14] Kaplan R. S. and Norton D. P., (1996) "Translating strategy into action: The balanced scorecard", Harvard Business School Press, Boston, Mass 1996.

[15] McNurlin B. C. and Sprague R. H. (2002), "Information Systems Management in Practice" fifth edition, Prentice-Hall International, Inc. Pages 211 - 214.

[16] Mumford Enid, (2001) "Advice for an action researcher", Information technology and people, MCB University Press, Vol. 14 No.1, pp 12 - 27.

[17] Neely A., Mills J., Gregory M., Richard H., Platts K. and Bourne M., (1996) "Getting the measure of your business", University of Cambridge, Manufacturing Engineering Group, Mill Lane, Cambridge.

[18] Neely A. and Adams C. (2001) "The Performance Prism Perspective", Journal of Cost Management, January/February 2001.

[19] Nudurupati S. S. and Bititci U. S. (2002) "Review of Performance Management Information Systems (PerforMIS)", Internal Report, Centre for Strategic Manufacturing, DMEM, University of Strathclyde, UK. (currently under review)

[20] Pannirselvam, G.P., Ferguson, L.A., Ash, R.C., Siferd, S.P. (1999) "Operations management research, an update for the 1990 s", Journal of Operations Management, Vol. 18, pp. $95-112$

[21] Suwingnjo P., Bititci U. S. and Carrie A. S., (1997), "Quantitative Models for Performance Measurement System: An Analytical Hierarchy Process Approach", Managing Enterprises - Stakeholders, Engineering, Logistics, and Achievement, Mechanical Engineering Publications Ltd., pp. 237 - 243.

[22] Thomas P. Ryan (2000) "Statistical Methods for Quality Improvement." Second edition, A Wiley Interscience Publication, John Wiley \& Sons, INC.

[23] Turner T. J. and Bititci U. S., (1997) "Maintaining reliability of business processes using active monitoring techniques." International Journal of Business Performance Measurement, Vol. 2. 